\title{
Noticias sobre a Enfermagem Brasileira na pandemia da COVID-19
}

\author{
News on Brazilian Nursing in the COVID-19 pandemic \\ Noticias sobre enfermería brasileña durante la pandemia de COVID-19 \\ Neyson Pinheiro Freire ${ }^{1,2}$ (1) https://orcid.org/0000-0002-9038-9974 \\ Daniel Amaral de Castro ${ }^{2,3}$ io hitps://orcid.org/0000-0003-3733-4613 \\ Maria Clara Marques Fagundes ${ }^{2,4}$ it nttps://orcid. org/0000-0003-4000-5655 \\ Francisco Rosemiro Guimarães Ximenes Neto ${ }^{1,2,5}$ io https://orcid.org/0000-0002-7905-9990 \\ Isabel Cristina Kowal OIm Cunhat io https://orcid.org/0000-0001-6374-5665 \\ Manoel Carlos Neri da Silva² io https://orcid.org/0000-0002-3923-7473
}

Como citar:

Freire NP, Castro DA, Fagundes MC, Ximenes Neto FR, Cunha IC, Silva MC. Notícias sobre a Enfermagem Brasileira na pandemia da COVID-19. Acta Paul Enferm. 2021;34: AAPE02273.

DOI

http://dx.doi.org/10.37689/actaape/2021A002273

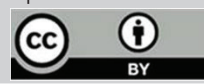

Descritores

Enfermagem; Pandemia; COVID-19; Notícias; Brasi

Keywords

Nursing; Pandemics; COVID-19; News; Brazil

\section{Descriptores}

Enfermería; Pandemia; COVID-19; Noticias; Brasi

Submetido 19 de Agosto de 2020

Aceito

5 de Março de 2021

\section{Autor correspondente}

Neyson Pinheiro Freire

E-mail: neysonfreire@gmail.com

\section{Resumo}

Objetivo: Analisar 0 impacto e a visibilidade que as matérias jornalísticas trouxeram para a Enfermagem brasileira durante a pandemia da COVID-19.

Métodos: Estudo documental, desenvolvido com base nas informações coletadas em sites de notícias, telejornais, programa de rádio e imprensa escrita, por meio de clipping; bem como pelo acompanhamento de demandas atendidas pela Assessoria de Comunicação do Conselho Federal de Enfermagem (COFEN), a partir de matérias de alcance nacional e internacional, que após seleção, foram sistematizadas com base no referencial da análise de conteúdo.

Resultados: Foram selecionadas 136 reportagens de grandes veículos de comunicação veiculadas de 16 março a 31 maio de 2020, e sua análise permitiu identificar os padrões narrativos, classificados em três categorias temáticas, que são: Protagonismo Político e Profissional da Enfermagem Brasileira, Condiçoes de Trabalho dos Profissionais da equipe Enfermagem e Vulnerabilidade, Adoecimento e Morte de Profissionais de Enfermagem.

Conclusão: As reportagens contribuíram para dar uma maior visibilidade ao trabalho da equipe de Enfermagem, bem como alertar para as precárias condições de trabalho a que estão expostos, além de sensibilizar a opinião pública sobre 0 avanço da doença entre os profissionais da equipe de Enfermagem.

\section{Abstract}

Objective: To analyze the impact and visibility that journalistic news brought to Brazilian Nursing during the COVID-19 pandemic.

Methods: Documentary study developed based on information collected from news sites, news programs, radio programs and written press through clipping; as well as the monitoring of demands performed by the Communication Office of the Federal Nursing Council (Portuguese acronym: COFEN), based on articles of national and international scope. After selection, these were systematized based on the content analysis framework.

Results: One hundred and thirty-six news from mass media published from March 16 to May 31, 2020 were selected. Through the analysis, narrative patterns were identified and classified into three thematic categories, namely: Political and Professional Protagonism of Brazilian Nursing; Working Conditions of Nursing Professionals; and Vulnerability, Illness and Death of Nursing Professionals. 
Conclusion: The news contributed to give greater visibility to the work of the Nursing team, warn of the precarious working conditions to which they are exposed, and raise public awareness of the disease progress among Nursing team professionals.

\section{Resumen}

Objetivo: Analizar el impacto y la visibilidad que las notas periodísticas proporcionaron a la enfermería brasileña durante la pandemia de COVID-19.

Métodos: Estudio documental, desarrollado con base en información recopilada en sitios web de noticias, noticieros televisivos, programas de radio y prensa escrita, por medio de clipping, así como también mediante el seguimiento de demandas atendidas por la Asesoría de Comunicación del Consejo Federal de Enfermería (COFEN), a partir de notas de alcance nacional e internacional que, luego de la selección, fueron sistematizadas con base en el marco referencial del análisis de contenido.

Resultados: Se seleccionaron 136 notas de grandes vehículos de comunicación publicadas del 16 de marzo al 31 de mayo de 2020 . Su análisis permitió identificar los patrones narrativos, clasificados en tres categorías temáticas, a saber: Protagonismo político y profesional de la enfermería brasileña, Condiciones de trabajo de los profesionales del equipo de enfermería y Vulnerabilidad, enfermedad y muerte de profesionales de enfermería.

Conclusión: Las notas contribuyeron para dar una mayor visibilidad al trabajo del equipo de enfermería, así como también para advertir sobre las precarias condiciones de trabajo a las que están expuestos, además de sensibilizar la opinión pública sobre el avance de la enfermedad entre los profesionales del equipo de enfermería.

\section{Introdução}

O primeiro caso do novo coronavírus (COVID-19/ Sars-CoV-2) na China foi identificado em um residente de 55 anos, da cidade de Wuhan, província de Hubei, com rastreamento epidemiológico datado em meados de novembro de 2019, sendo este noticiado pelo site South China Morning Post. ${ }^{(1)} \mathrm{O}$ rápido avanço de casos do novo coronavírus, sobretudo para além da China, atingindo milhôes de pessoas no mundo, levou a Organização Mundial da Saúde (OMS), em 30 de janeiro de 2020, a declarar emergência global de interesse internacional. ${ }^{(2-5)}$

Devido a rápida expansão e disseminação da COVID-19 para 114 países, registrando 118.999 casos e 4.291 óbitos, a gravidade da situação levou a OMS, em 11 de março, a elevar o grau de risco à humanidade e a classificar a situação mundial como pandemia. ${ }^{(6)}$ A doença tornou-se uma ameaça global à saúde pública em larga escala, levando a adoção de medidas como o fechamento de fronteiras por diversos países. Com isso, governos de todo o mundo, implementaram importantes medidas de prevençáo, incluindo exames de viagem para controlar a disseminação do vírus. ${ }^{(7)}$

A pandemia da COVID-19 é o principal assunto nos dias de hoje, na imprensa, nas mídias digitais, no debate popular e político e nas páginas da literatura científica. Esta realidade é decorrente do impacto causado pela crise na vida das pessoas, do medo, e, sobretudo, do desconhecimento sobre o comportamento da doençae suas reais consequências. ${ }^{(8)}$ A COVID-19 tem se espalhado por um mundo altamente conectado, no qual virtualmente todas as pessoas estão liga- das entre si pelo telefone celular, usando redes sociais digitais globais, como o Facebook ou o Twitter, para facilitar a interação humana e o compartilhamento de informaçôes sobre o vírus. ${ }^{(9)}$

A COVID-19 tem influenciado o cotidiano das pessoas, a começar pela obrigatoriedade em seguir regras de isolamento social, até o planejamento e a adoção de medidas de saúde para enfrentar a crise. O fato é que a COVID-19 impregnou-se de forma dominante, sobretudo na vida dos profissionais da saúde que estáo no front do combate do novo coronavírus. No mundo, vemos a solidariedade da populaçáo para com os profissionais da saúde. No entanto, essa manifestação não deve ocorrer somente por meio de "campanhas de palmas", mas também pela mitigação da carga de trabalho sobre suas famílias, pois elas estáo submetidas a estresse, isolamento e sofrimento emocional de intensidade excepcional. ${ }^{(10)}$

Neste contexto, os profissionais de Enfermagem ganharam destaque no combate ao novo coronavírus, por constituírem mais da metade dos trabalhadores da saúde no Brasil e no mundo, tendo ampla capilaridade territorial, eles são essenciais no combate à doença, contra a qual não há, ainda, vacina ou tratamento comprovadamente eficaz. O cuidado baseado no manejo clínico dos sintomas, no atendimento às necessidades básicas, fortalece o papel da categoria.

Entretanto, pela falta de acesso e escassez de Equipamentos de Proteção Individual (EPI), o sub dimensionamento de profissionais nas equipes, a exposiçâao de grupos de risco, a necessidade de educação permanente e o estabelecimento de políticas públicas conflituosas para o combate ao vírus e mi- 
tigação da doença, os profissionais de Enfermagem brasileiros foram os trabalhadores da saúde mais afetados pela COVID-19.

O Observatório da Enfermagem, criado pelo Conselho Federal de Enfermagem (COFEN) para monitorar casos de COVID-19 na profissão, já contabilizava em 10 de agosto mais de 32 mil enfermeiros, técnicos e auxiliares de enfermagem afastados por suspeita de COVID-19. Destes, 15.642 já testaram positivo para o novo coronavírus e 340 foram a óbito, uma taxa de letalidade de $1,96 \%,{ }^{(11)}$ representando o maior quantitativo de trabalhadores da saúde afetados no mundo. Com esta realidade, a Enfermagem brasileira emergiu como uma das principais fontes institucionais de informaçóes para o jornalismo nacional e internacional, tornando-se evidente na mídia diariamente, o que nos motivou a desenvolver o presente estudo, que tem como objetivo analisar o impacto e a visibilidade que as matérias jornalísticas trouxeram para a Enfermagem brasileira durante a pandemia da COVID-19.

\section{Métodos}

Pesquisa documental, desenvolvida com base nas informaçóes coletadas em sites de notícias, telejornais, programa de rádio e imprensa escrita, por meio de clipping (monitoramento, análise e arquivamento de mençóes efetuadas pela mídia), bem como pelo acompanhamento de demandas atendidas pela Assessoria de Comunicação do Cofen, durante o período de 16 de março a 31 de maio de 2020.

$\mathrm{O}$ estudo foi desenvolvido com base em informaçôes da imprensa escrita, telejornais e mídias digitais de alcance nacional e internacional, de acesso aberto/livre. Aqueles com acesso restrito a assinantes também foram utilizados como fonte de informação, após a assinatura digital pelos pesquisadores.

A base inicial foi levantada por meio de clippagem do Google, utilizando as palavras-chave "Enfermagem", "COFEN" e "Conselho Federal de Enfermagem", além da busca ativa com estas palavras-chave e o acompanhamento das demandas atendidas pela Assessoria de Comunicação do Cofen.
O critério de inclusão foi ter "alcance nacional”, prevalecendo veículos sediados em Brasília, Rio de Janeiro e São Paulo, o que reflete a própria estrutura centralizada da indústria de comunicação e informação no Brasil. Quanto aos jornais de impacto internacional, foram selecionados aqueles veículos de comunicação de massa, que buscaram a Assessoria de Comunicação do COFEN, em busca de pautas sobre a Enfermagem Brasileira, a exemplo dos americanos "New York Times", "Wall Street Journal" e "Bloomberg", o australiano "ABC News", o espanhol "El País", o francês "France 24", o chileno "El Ciudadano", o venezuelano "Telesur", o sul-coreano "KBS", o russo "Sputnik", e os britânicos "Daily Mail" e "The Guardian".

Foram excluídas reportagens publicadas em veículos que não possuíam abrangência nacional, considerando aspectos como acesso, tiragem, visualizaçóes e impacto. Foram excluídos também publieditoriais e matérias veiculadas por canais institucionais, ainda que de alcance nacional, como a "TV Justiça" e a "Agência Senado", buscando uma representação fidedigna da "grande imprensa". Nos casos em que a mesma reportagem foi publicada por diferentes veículos, considerou-se apenas uma delas, sendo selecionado o veículo de maior abrangência. Foram identificadas 183 reportagens, que atendiam aos critérios e tinham como temática a pandemia de COVID-19, explícita no título ou lide. Com base nos critérios de exclusão, resultaram 136 reportagens.

As informaçóes foram coletadas referentes ao período de 16 de março a 31 de maio de 2020, e catalogadas em uma planilha do Excel $^{\circledR}$, com a transcrição dos conteúdos e falas nas diferentes línguas. Após sistematização, estas foram analisadas pelo método análise de conteúdo, embasado, no referencial de Minayo, ${ }^{(12)}$ utilizando-se a técnica da análise temática, que envolve a pré-análise, a exploração do material e o tratamento dos resultados, leitura flutuante; constituição do corpus; formulação de hipóteses e objetivos; recorte do texto em unidades de registro; identificação dos núcleos de sentidos, e a classificação e agregação das informaçóes. ${ }^{(12)}$

A definiçáo das categorias demandou análise qualitativa do conteúdo das reportagens, de modo 
a identificar padróes narrativos, que também são objeto do presente estudo. Trata-se não somente de metrificar o alcance da Enfermagem como fonte durante a pandemia da COVID-19, mas, sobretudo de avaliar seu efeito na narrativa jornalística e as temáticas de maior repercussão para as condiçôes de trabalho e visibilidade profissional vivenciada pela categoria, em um momento tão diverso quanto é este da pandemia, em que toda rede de serviços e processos de trabalho dos profissionais da saúde passam por um novo reordenamento. Neste sentido, após a verificaçáo detalhada do conteúdo das reportagens, emergiram três categorias temáticas, que são: "Protagonismo Político e Profissional da Enfermagem Brasileira", "Condiçôes de Trabalho dos Profissionais de Enfermagem" e "Vulnerabilidade, Adoecimento e Morte de Profissionais de Enfermagem”. Com a definição das categorias, as informaçóes foram sistematizadas em quadros e, em seguida, os títulos das reportagens inseridos no programa "Wordart.com" ferramenta para a construção das nuvens de palavras para cada categoria, o que caracterizou o produto da análise temática dos conteúdos. ${ }^{(12)}$

Os aspectos éticos, como transparência e publicidade, foram observados e cumpridos na execução da pesquisa, que se baseia em reportagens já publicadas por veículos de comunicação (impressa, televisiva, radiofônica e digital), com veiculação aberta, e não envolve, portanto, qualquer risco adicional aos autores das reportagens, pessoas entrevistadas e veículos. Mesmo assim, foram respeitados os princípios éticos e legais das pesquisas envolvendo seres humanos, conforme o emanado pelas Resoluçôes $n^{\circ}$ 466/2012 e no 510/2016 do Conselho Nacional de Saúde (CNS).

\section{Resultados}

O protagonismo dos profissionais em notícias nos principais veículos de comunicação, efetuando denúncias sobre as condições de trabalho (como a ausência de insumos e EPI, situação das unidades de saúde e a realidade de como está sendo enfrentada a pandemia no país), a vulnerabilidade, o adoeci- mento e morte, inseriu a Enfermagem brasileira no cotidiano da mídia nacional e mundial.

Das 136 reportagens selecionadas para este estudo, quanto aos meios de comunicação, estão assim distribuídas: $66,2 \%$ são sites de notícias (Internet), incluindo veículos com ediçôes impressas, 25,0\% em telejornais (TV), 7,4\% em emissoras de radiodifusão (Rádio), e 0,7\% em programa de auditório (TV). Os resultados estão apresentados a partir das categorias identificadas no estudo.

\section{Categoria 1 - "Protagonismo Político e Profissional da Enfermagem Brasileira"}

Ao analisar a evolução das temáticas das notícias, estas tiveram início com as denúncias da falta de acesso, controle ou escassez de EPI, que foram predominantes na chegada da pandemia no país, sendo posteriormente, observado aumento de matérias que destacavam o avanço da doença e as mortes de profissionais, bem como o protagonismo político e profissional da Enfermagem. Esta categoria representou $17,7 \%$ dos achados, que estão descritos no quadro 1.

No quadro 1, predominam reportagens nos seguintes meios de comunicação: 70,1\% em sites de notícias (Internet), incluindo jornais que contam também com ediçôes impressas, 16,7\% em telejornais (TV), 12,5\% em emissoras de radiodifusão (Rádio), relativas a atuação política de profissionais e entidades da Enfermagem frente aos desafios enfrentados com a pandemia de COVID-19, bem como o protagonismo profissional diante às adversidades e homenagens de pessoas públicas, a exemplo de personalidades religiosas e artistas plásticos. Na figura 1 é apresentada a nuvem de palavras que permite melhor visualização das palavras mais citadas.

\section{Categoria 2 - "Condições de Trabalho dos Profissionais de Enfermagem"}

Esta categoria representou 23,5\% dos achados. Dentre as 30 matérias iniciais, 63\% abordaram a insuficiência de EPI, demonstrando que era a principal fonte de preocupação, quando o vírus ainda não havia chegado ao Brasil, conforme a descrição das matérias no quadro 2 . 
Quadro 1. Descrição das notícias sobre o Protagonismo Político e Profissional da Enfermagem Brasileira, durante a Pandemia da COVID-19

\begin{tabular}{|c|c|c|c|c|}
\hline $\mathrm{N}^{0}$ & VEÍCULO & DATA & MANCHETE/ASSUNTO & MEIO \\
\hline 1 & EBC & $21 / 03$ & Profissionais de saúde fazem campanha na internet para pedir que as pessoas fiquem em casa. & Agência de Notícias - Internet \\
\hline 2 & Folha de São Paulo & 25/03 & Congresso, governadores, Judiciário, empresários e até aliados reagem à fala de Bolsonaro. & Jornal - Internet \\
\hline 3 & Rádio Web & $27 / 03$ & Entidades ignoram Bolsonaro e seguem recomendações da OMS. & Agência de Notícias - Rádio \\
\hline 4 & CNN & 29/03 & Cuidado tomado pelos profissionais e criação do Observatório. & TV \\
\hline 5 & Rádio Web & $01 / 04$ & Observatório vai acompanhar saúde de enfermeiros após três mortes. & Agência de Notícias - Rádio \\
\hline 6 & G1 & $13 / 04$ & $\begin{array}{l}\text { MEC flexibiliza antecipação de formatura em áreas da saúde e exclui atuação 'exclusivamente' no } \\
\text { combate à pandemia. }\end{array}$ & Jornal Digital \\
\hline 7 & EBC & 29/04 & Conselho denuncia uso de capa de chuva como avental por profissionais de saúde. & Agência de Notícias - Internet \\
\hline 8 & EBC & $30 / 04$ & Câmara aprova prioridade a profissionais de saúde e agentes funerários em testes para COVID-19. & Agência de Notícias - Internet \\
\hline 9 & 0 Globo & $01 / 05$ & Enfermeiros fazem homenagem a colegas mortos pela COVID-19, já são 65 mortes. & Jornal - Internet \\
\hline 10 & UOL & 02/05 & Conselho identifica e diz que vai processar agressores de enfermeiros. & Jornal Digital \\
\hline 11 & $\begin{array}{l}\text { Rede Globo } \\
\text { Jornal Hoje }\end{array}$ & 05/05 & PGR pede investigação de agressão a enfermeiros em protesto no Dia do Trabalhador. & TV \\
\hline 12 & $\begin{array}{l}\text { Rede Globo } \\
\text { Jornal Nacional }\end{array}$ & 05/05 & MP pede inquérito policial sobre agressões a enfermeiros e jornalistas em manifestações. & TV \\
\hline 13 & IstoÉ & 06/05 & Empresário diz que criticou protesto de enfermeiros por achar que ato era falso. & Revista - Internet \\
\hline 14 & EBC & 07/05 & Conselho de Enfermagem recebe mais de 6 mil denúncias sobre falta de equipamentos de proteção. & Agência de Notícias - Internet \\
\hline 15 & Exame & $08 / 05$ & Obra de Banksy mostra enfermeiras como heroínas da vida real. & Revista - Internet \\
\hline 16 & EBC & $12 / 05$ & COFEN defende melhores condições de trabalho para enfermeiros. & Agência De Notícias - Internet \\
\hline 17 & Telesur & $12 / 05$ & Enfermeras celebran su día luchando contra el coronavirus. & Multimídia - Internet \\
\hline 18 & Folha de São Paulo & $12 / 05$ & Pioneiras da enfermagem são homenageadas pela Turma da Mônica. & Jornal - Internet \\
\hline 19 & RadioWeb & $12 / 05$ & Dia Internacional da Enfermagem: 200 anos de coragem e cuidado & Agência de Notícias - Rádio \\
\hline 20 & Folha de São Paulo & $13 / 05$ & Sob ataque e recorde de mortes, enfermagem recebe homenagem do Papa Francisco. & Jornal - Internet \\
\hline 21 & France 24 & $13 / 05$ & "World's highest death rate": Brazil's nurses protest as fatalities mount. & TV \\
\hline 22 & Estadão & $13 / 05$ & Profissionais da saúde divulgam carta pedindo o fim da circulação de fake news sobre coronavírus. & Jornal - Internet \\
\hline 23 & Estadão & $15 / 05$ & Enfermagem: 0 essencial não é mais invisível aos olhos. & Jornal - Internet \\
\hline 24 & Folha de São Paulo & $17 / 05$ & Enfermeiros querem aproveitar visibilidade na pandemia para aprovar piso salarial. & Jornal - Internet \\
\hline
\end{tabular}

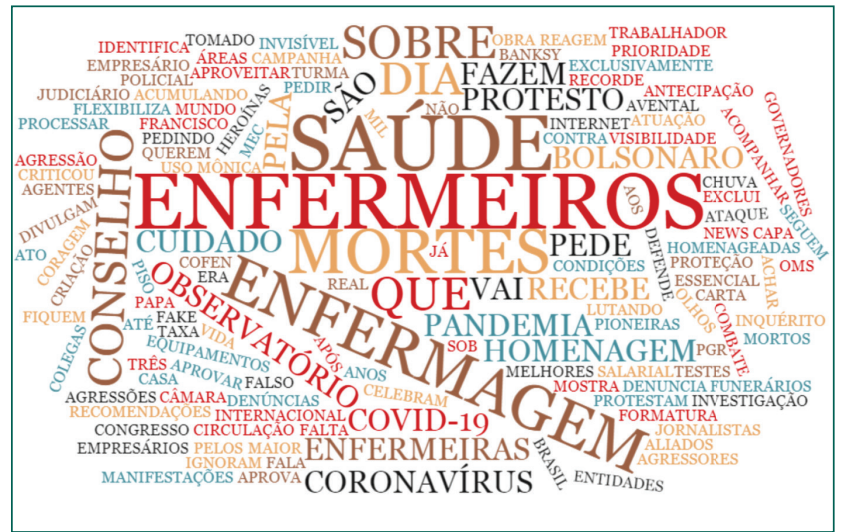

Figura 1. Nuvem de palavras representativa da Categoria 1 Protagonismo Político e Profissional da Enfermagem Brasileira
No quadro 2, predominam reportagens nos seguintes meios de comunicação: $50,0 \%$ em sites de notícias (Internet), 40,6\% em telejornais (TV) e 9,4\% em emissoras de radiodifusão (Rádio), relativas às condiçôes de trabalho insatisfatórias e, sobretudo, pela precarização e dificuldade de acesso aos EPI, a exemplo de máscara cirúrgica e N95, capote/ avental, proteção ocular (óculos ou máscara facial), entre outros. Na nuvem de palavras mostrada na figura 2, também podem-se destacar as palavras Falta profissionais, proteção, enfermeiros, denúncias, entre outras mais citadas nas reportagens.

Quadro 2. Descrição das notícias sobre o Condições de Trabalho dos Profissionais de Enfermagem, durante a Pandemia da COVID-19

\begin{tabular}{|l|l|l|l|l|l|}
\hline$N^{0}$ & VEíCULO & DATA & MANCHETE/ASSUNTO & MEI0 & Revista - Internet \\
\hline 1 & Marie Claire & $19 / 03$ & Como estão as enfermeiras que estão na linha de frente contra o coronavírus. & TV \\
\hline 2 & $\begin{array}{l}\text { Rede Globo } \\
\text { Fantástico }\end{array}$ & $22 / 03$ & Dráuzio Varella mostra os profissionais de saúde que estão combatendo o coronavírus. & Jornal - Internet \\
\hline 3 & Folha de São Paulo & $23 / 03$ & Além de longas jornadas, enfermeiras enfrentam falta de protocolo e de equipamentos de proteção. & TV - Internet \\
\hline 4 & CNN & $26 / 03$ & Conselho de Enfermagem recebe 1271 denúncias de falta de equipamento de proteção. & Jornal - Internet \\
\hline 5 & Estadão & $29 / 03$ & Com falta de itens de proteção e médicos, País pode ter "apagão" de mão de obra. & TV \\
\hline 6 & $\begin{array}{l}\text { Rede Globo } \\
\text { Fantástico }\end{array}$ & $29 / 03$ & Profissionais de saúde relatam falta de equipamentos de proteção; denúncias passam de 4 mil. & TV \\
\hline 7 & $\begin{array}{l}\text { Rede Record } \\
\text { Domingo Espetacular }\end{array}$ & $29 / 03$ & Domingo Espetacular visita hospitais de campanha em funcionamento. & \\
\hline
\end{tabular}




\begin{tabular}{|c|c|c|c|c|}
\hline NNo $^{\circ}$ & VEÍCULO & DATA & MANCHETE/ASSUNTO & MEIO \\
\hline 8 & $\begin{array}{l}\text { SBT } \\
\text { Conexão Repórter }\end{array}$ & $30 / 03$ & Conexão Repórter mostra real situação de hospitais no combate ao coronavírus. & TV \\
\hline 9 & $\begin{array}{l}\text { Rede Record } \\
\text { Hoje em Dia }\end{array}$ & $31 / 03$ & Profissionais de saúde relatam falta de EPI. & TV \\
\hline 10 & El País & $02 / 04$ & Sem material de proteção, profissionais de saúde relatam apreensão após mortes de dois enfermeiros em São Paulo. & Jornal Digital \\
\hline 11 & BandNews & $03 / 04$ & A rede hospitalar pode sentir efeitos da falta de profissionais. & Rádio \\
\hline 12 & $\begin{array}{l}\text { Rede Record } \\
\text { Domingo Espetacular }\end{array}$ & 05/04 & Médicos e enfermeiros revelam como é a rotina na linha de frente no combate ao coronavírus. & TV \\
\hline 13 & $\begin{array}{l}\text { Globo } \\
\text { Jornal Hoje }\end{array}$ & $06 / 04$ & Denúncias por falta de EPI entre profissionais da saúde aumentam 14\% na AMB. & TV \\
\hline 14 & CNN & 08/04 & Situação dos trabalhadores da saúde no Brasil. & TV \\
\hline 15 & BBC & 09/04 & $\begin{array}{l}\text { Durmo no terraço para não infectar minha mãe', diz técnico em enfermagem que ganha } \mathrm{R} \$ 80 \text { por plantão de } 12 \\
\text { horas. }\end{array}$ & Jornal Digital \\
\hline 16 & $\begin{array}{l}\text { Rede Globo } \\
\text { Jornal Nacional }\end{array}$ & $11 / 04$ & Profissionais da saúde reclamam da falta de equipamentos de proteção individual. & TV \\
\hline 17 & BandNews & $13 / 04$ & Profissionais de saúde denunciam falta de EPI. & Rádio \\
\hline 18 & Sputnik & $15 / 04$ & Enfermeros de Brasil prevén graves problemas por falta de protección ante COVID-19. & Jornal Digital \\
\hline 19 & CNN & $15 / 04$ & Podcast E Tem Mais - Falta material de proteção contra a pandemia. & Multimídia Internet \\
\hline 20 & Telesur & $15 / 04$ & Denuncian falta de insumos para personal de salud en Brasil. & Multimídia - Internet \\
\hline 21 & 0 Globo & $16 / 04$ & Vídeo mostra pacientes dividindo ala de hospital com mortos por suspeita de COVID-19 em Manaus. & Jornal - Internet \\
\hline 22 & $\begin{array}{l}\text { Rede Record } \\
\text { Domingo Espetacular }\end{array}$ & $19 / 04$ & Falta de equipamentos de proteção traz risco a profissionais da saúde e pacientes. & TV \\
\hline 23 & G1 & $21 / 04$ & $\begin{array}{l}\text { Em } 1 \text { mês, médicos registraram 3,1 mil denúncias de falta de equipamentos de proteção para atuar contra } 0 \\
\text { coronavirus, diz associação. }\end{array}$ & Jornal Digital \\
\hline 24 & R7 & 28/04 & Cidades do interior enfrentam medo e falta de estrutura contra COVID-19. & Jornal Digital \\
\hline 25 & KBS & $02 / 05$ & Brasil, infecção grave e morte da equipe de saúde... Falta de equipamento de proteção. & TV \\
\hline 26 & Exame & 01/05 & Enfermeiros protestam por condições melhores de trabalho no País. & Revista - Internet \\
\hline 27 & SBT & $07 / 05$ & Profissionais denunciam falta de equipamentos de proteção individual. & TV \\
\hline 28 & CNN & 09/05 & COVID-19: Mulheres representam 85\% de Enfermeiros. & TV \\
\hline 29 & R7 & $12 / 05$ & $\begin{array}{l}\text { "Todos os dias, a gente ouve que mais colegas adoeceram e morreram por conta da COVID-19", declara porta-voz do } \\
\text { COFEN. }\end{array}$ & Internet \\
\hline 30 & El Ciudadano & $12 / 05$ & Brasil es un peligro para Sudámérica: rumbo a ser epicentro mundial de COVID-19. & Internet \\
\hline 31 & New York Times & $16 / 05$ & Brazil, Once a Leader, Struggles to Contain Virus Amid Political Turmoil. & Jornal - Internet \\
\hline 32 & Época & 19/05 & Maior parte dos profissionais de enfermagem com coronavírus é da faixa dos 30 anos. & Revista - Internet \\
\hline
\end{tabular}

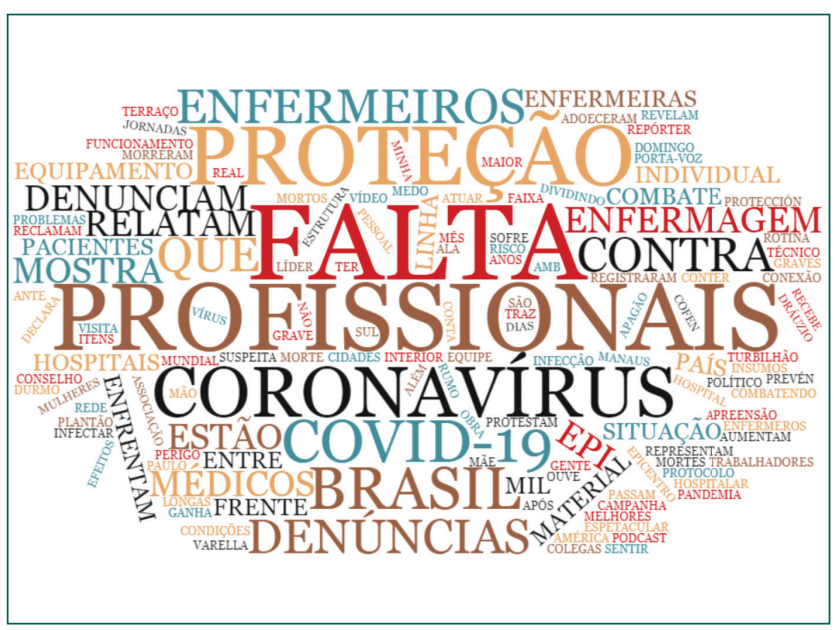

Figura 2. Nuvem de palavras representativa da Categoria 2 Condições de Trabalho dos Profissionais de Enfermagem

\section{Categoria 3 "Vulnerabilidade, Adoecimento e Morte de Profissionais de Enfermagem"}

Esta categoria representou 58,8\% dos achados identificados. A primeira morte de um profissional de
Enfermagem foi registrada no dia 20 de março, mas não é este o marco temporal relacionado à cobertura midiática. Somente após a criação do Observatório da Enfermagem do COFEN, ${ }^{(1)}$ em 29 de março, os afastamentos e óbitos de profissionais emergem como pauta diária na mídia. Estes resultados e outros estão descritos no quadro 3 .

No quadro 3, predominam reportagens nos seguintes meios de comunicação: $72,5 \% \mathrm{em}$ sites de notícias (Internet), incluindo veículos com edição impressa, $21,3 \%$ reportagens em telejornais (TV), 5,0\% em emissoras de radiodifusão (Rádio), e 1,2\% reportagem em programa de auditório (TV), relativas aos dados do Observatório de Enfermagem do COFEN apontam que as condiçôes de trabalho vulnerabilizam os profissionais de Enfermagem ao adoecimento e a morte. A nuvem de palavras mostrada na figura 3 também evidencia os aspectos destacados nesta categoria. 


\section{Quadro 3. Descrição das notícias sobre a Vulnerabilidade, Adoecimento e Morte de Profissionais de Enfermagem, durante a Pandemia da COVID-19}

\begin{tabular}{|c|c|c|c|c|}
\hline $\mathrm{N}^{0}$ & VEÍCULO & DATA & MANCHETE/ASSUNTO & MEIO \\
\hline 1 & $\mathrm{BBC}$ & $16 / 03$ & $\begin{array}{l}\text { "Achei que tinha sido infectada ao atender paciente": a rotina de profissionais de saúde que cuidam } \\
\text { de casos de coronavírus no Brasil. }\end{array}$ & Jornal Digital \\
\hline 2 & $\mathrm{BBC}$ & $24 / 03$ & $\begin{array}{l}\text { "Cuidamos dos outros, mas ninguém cuida de nós": as enfermeiras expostas ao coronavírus por falta } \\
\text { de equipamentos. }\end{array}$ & Jornal Digital \\
\hline 3 & Agência Pública & $27 / 03$ & Profissionais de saúde: "ou a gente se cuida, ou adoece". & Agência de Notícias - Internet \\
\hline 4 & Rádio Web & $30 / 03$ & Profissionais de enfermagem buscam atendimento psicológico. & Rádio \\
\hline 5 & CBN & $31 / 03$ & Profissionais de Enfermagem recebem apoio emocional durante a pandemia da Covid-19. & Rádio \\
\hline 6 & Folha de São Paulo & $06 / 04$ & Podcast debate pressões de pandemia sobre sistema e profissionais de saúde. & Jornal - Internet \\
\hline 7 & UOL & $07 / 04$ & Coronavírus: Conselho contabiliza óbitos de 16 profissionais de enfermagem. & Jornal Digital \\
\hline 8 & 0 Globo & $07 / 04$ & Brasil tem oito enfermeiros mortos por coronavírus, e outros nove óbitos aguardam confirmação. & Jornal - Internet \\
\hline 9 & G1 & $07 / 04$ & Casos de coronavírus no Brasil em 7 de abril. & Jornal Digital \\
\hline 10 & CBN & $08 / 04$ & Conselho contabiliza óbitos de profissionais de saúde por COVID-19. & Rádio \\
\hline 11 & $\begin{array}{l}\text { Rede Record } \\
\text { Fala Brasil }\end{array}$ & $10 / 04$ & Técnico de enfermagem morre vítima de coronavírus. & TV \\
\hline 12 & Época & $11 / 04$ & Na linha de frente do combate, profissionais de saúde são diagnosticados com COVID-19. & Revista - Internet \\
\hline 13 & $\begin{array}{l}\text { Rede Globo } \\
\text { Fantástico }\end{array}$ & $12 / 04$ & COVID-19 faz vítimas entre profissionais da saúde no Brasil. & TV \\
\hline 14 & Época & $13 / 04$ & Grupos de psicólogos oferecem atendimento voluntário a profissionais de Saúde. & Revista -Internet \\
\hline 15 & CNN & $13 / 04$ & Coronavírus já contaminou 237 profissionais de enfermagem no país. & TV \\
\hline 16 & 0 Globo & $13 / 04$ & No Brasil, 14 enfermeiros morreram por coronavírus, e outras 12 mortes estão em investigação. & Jornal - Internet \\
\hline 17 & Estadão & $14 / 04$ & Coronavírus: Conselho revela 29 mortes de enfermeiros e 36 mil denúncias por falta de EPI. & Jornal - Internet \\
\hline 18 & UOL & $14 / 04$ & $\begin{array}{l}\text { Morto com sintomas de COVID-19, técnico de enfermagem não pôde ler em CTI mensagem de } \\
\text { despedida da noiva. }\end{array}$ & Jornal Digital \\
\hline 19 & Revista Piauí & $16 / 04$ & 0 medo veste branco. & Revista - Internet \\
\hline 20 & RedeTV & $17 / 04$ & COVID-19: 30 profissionais da saúde morreram no Brasil, diz Conselho. & TV \\
\hline 21 & IstoÉ & $17 / 04$ & Os gargalos da saúde. & Revsita - Internet \\
\hline 22 & G1 & $17 / 04$ & $\begin{array}{l}\text { Brasil tem } 30 \text { mortes de profissionais de enfermagem por coronavírus e mais de } 4 \text { mil afastados pela } \\
\text { doença. }\end{array}$ & Internet \\
\hline 23 & 0 Globo & $19 / 04$ & Pandemia leva ao extremo quem trabalha na rede pública de Saúde. & Internet \\
\hline 24 & $\begin{array}{l}\text { Rede Globo } \\
\text { Fantástico }\end{array}$ & $19 / 04$ & Superlotação das UTI: Fantástico mostra a situação crítica em capitais por causa da COVID-19. & TV \\
\hline 25 & EBC & $20 / 04$ & Profissionais de saúde devem ter cuidado com pressão e estresse. & Agência de Notícias - Internet \\
\hline 26 & Rede Globo & $21 / 04$ & Encontro com Fátima Bernardes - Rosana se demitiu de hospital por medo da COVID-19. & TV \\
\hline 27 & 0 Globo & $22 / 04$ & $\begin{array}{l}\text { Coronavírus: quatro enfermeiras relatam o cotidiano exaustivo de quem está na linha de frente do } \\
\text { combate à COVID-19. }\end{array}$ & Jornal - Internet \\
\hline 28 & UOL & $23 / 04$ & Baixas na Saúde. & Internet \\
\hline 29 & Globo News & $23 / 04$ & Enfermeiros afastados por causa da Covid-19. & TV \\
\hline 30 & Estadão & $23 / 04$ & Brasil tem ao menos 38 mortes por coronavírus na enfermagem, diz COFEN. & Jornal Internet \\
\hline 31 & EBC & $24 / 04$ & Campanha "Juntos contra o coronavírus" tenta proteger profissionais de enfermagem. & Agência de Notícias - Internet \\
\hline 32 & 0 Globo & $26 / 04$ & Covid-19: Conselhos e psicólogos oferecem ajuda emocional online a profissionais de saúde. & Jornal - Internet \\
\hline 33 & $\begin{array}{l}\text { Rede Globo } \\
\text { Fantástico }\end{array}$ & $26 / 04$ & Profissionais de saúde lidam com medo e pressão no combate ao coronavírus. & TV \\
\hline 34 & $\mathrm{R} 7$ & $27 / 04$ & Brasil tem 4.602 profissionais de enfermagem afastados por COVID-19. & Jornal - Internet \\
\hline 35 & Época & $28 / 04$ & $\begin{array}{l}\text { "Não quero que passem por isso": } 0 \text { alerta da técnica em enfermagem em live feita dias antes de } \\
\text { morrer por COVID-19. }\end{array}$ & Revista- Internet \\
\hline 36 & Telesur & $28 / 04$ & Más de 4.000 enfermeros son suspendidos en Brasil por COVID-19. & Internet \\
\hline 37 & Rede Globo & $01 / 05$ & Encontro com Fátima Bernardes - Qual o sentimento dos Profissionais de Saúde? & TV \\
\hline 38 & El País & 02/05 & A luta contra o coronavírus tem o rosto de mulheres. & Jornal Digital \\
\hline 39 & BBC & 02/05 & $\begin{array}{l}\text { Coronavírus: "Alguns não vão conseguir mais colocar o pé numa UTI', dizem terapeutas de } \\
\text { profissionais da saúde. }\end{array}$ & Jornal Digital \\
\hline 40 & $\begin{array}{l}\text { Rede Globo } \\
\text { Fantástico }\end{array}$ & 03/05 & COVID-19 saturou o sistema de saúde das capitais brasileiras e avança para o interior do país. & TV \\
\hline 41 & CNN & 05/05 & Brasil ultrapassa EUA em mortes de profissionais de enfermagem por COVID-19. & Multimídia - Internet \\
\hline 42 & El País & $06 / 05$ & Brasil ya ha perdido a más enfermeros por el coronavírus que Italia y España. & Jornal Digital \\
\hline 43 & Sputnik Mundo & $06 / 05$ & Más de 10.000 enfermeros brasileños, apartados del trabajo por sospecha de COVID-19. & Jornal Digital \\
\hline 44 & G1 & $06 / 05$ & $\begin{array}{l}\text { Ao menos } 76 \text { profissionais de enfermagem morreram em decorrência da COVID-19 no Brasil, } \\
\text { segundo conselho da categoria. }\end{array}$ & Jornal Digital \\
\hline 45 & UOL & 06/05 & Brasil supera 10 mil enfermeiros afastados e 88 mortos, 0 dobro da Itália. & Jornal Digital \\
\hline 46 & GloboNews & 07/05 & 91 mortos e mais de 10 mil enfermeiros afastados por causa da COVID-19. & TV \\
\hline 47 & $\begin{array}{l}\text { Rede Globo } \\
\text { Jornal Hoje }\end{array}$ & 07/05 & Brasil tem mais mortes de enfermeiros do que a Itália. & TV \\
\hline
\end{tabular}




\begin{tabular}{|c|c|c|c|c|}
\hline $\mathrm{N}^{0}$ & VEÍCULO & DATA & MANCHETE/ASSUNTO & MEIO \\
\hline 48 & $\mathrm{R} 7$ & 08/05 & Brasil afasta 504 profissionais de enfermagem por COVID-19 em 24h. & Jornal Digital \\
\hline 49 & EBC & 08/05 & Número de profissionais de enfermagem que morreram de COVID-19 no Brasil é maior que o da Itália. & Agência De Notícias -Internet \\
\hline 50 & $\begin{array}{l}\text { Rede Record } \\
\text { Fala Brasil }\end{array}$ & $08 / 05$ & Profissionais em grupo de risco são obrigados a trabalhar na Grande SP. & TV \\
\hline 51 & $\begin{array}{l}\text { Rede Globo } \\
\text { Fantástico }\end{array}$ & $10 / 05$ & COVID-19: profissionais de Saúde estão expostos ao risco de contaminação por Covid-19. & TV \\
\hline 52 & UOL & $12 / 05$ & Levantamento aponta morte de 98 enfermeiros por coronavírus em 30 dias. & Jornal Digital \\
\hline 53 & $\begin{array}{l}\text { Band } \\
\text { Jornal da Band }\end{array}$ & $12 / 05$ & Profissão de risco no Brasil: 108 enfermeiros morreram de COVID-19. & TV \\
\hline 54 & Daily Mail & $12 / 05$ & $\begin{array}{l}\text { Nearly } 900 \text { die from the coronavirus in a 24-hour period as Brazil's President Bolsonaro challenges } \\
\text { reluctant governors by ordering gyms and hair salons to reopen. }\end{array}$ & Jornal -Internet \\
\hline 55 & $\begin{array}{l}\text { Rede Globo } \\
\text { Jornal da Globo }\end{array}$ & $12 / 05$ & Cento e oito profissionais de enfermagem já morreram por COVID-19. & TV \\
\hline 56 & ABC News & $13 / 05$ & $\begin{array}{l}\text { Brazil's coronavirus cases pass Germany's as President Jair Bolsonaro fights to open gyms, beauty } \\
\text { parlours. }\end{array}$ & Jornal Digital \\
\hline 57 & Uol & $13 / 05$ & "Minha mãe quis que eu pedisse demissão", diz enfermeiro que teve COVID-19. & Jornal Digital \\
\hline 58 & R7 & $14 / 05$ & Brasil tem 14.465 profissionais de enfermagem afastados por COVID-19. & Jornal Digital \\
\hline 59 & TV Brasil & $14 / 05$ & Mais de 30 mil profissionais de Saúde contraíram a COVID-19. & TV \\
\hline 60 & Uol & $15 / 05$ & $\begin{array}{l}\text { Coronavírus: Últimas notícias e o que sabemos até esta sexta-feira (15) - RJ: Estado tem recorde de } \\
\text { mortes de enfermeiros. }\end{array}$ & Jornal Digital \\
\hline 61 & Crescer & $15 / 05$ & $\begin{array}{l}\text { \#MãesnaSaúde: "Mãe, quando o coronavírus vai embora, para eu poder te dar um beijo?", diz filho de } \\
6 \text { anos à enfermeira. }\end{array}$ & Revista - Internet \\
\hline 62 & Uol & $15 / 05$ & Por que hospitais do RJ têm mais mortes de enfermeiros no país. & Jornal Digital \\
\hline 63 & RadioWeb & $16 / 05$ & Brasil já tem mais de 30 mil profissionais de saúde contaminados. & Rádio \\
\hline 64 & BBC & $17 / 05$ & $\begin{array}{l}\text { "Há um mês não vejo minha filha": enfermeiros vivem rotina de longas jornadas, baixos salários e, } \\
\text { agora, solidão. }\end{array}$ & Jornal Digital \\
\hline 65 & CGTN & $17 / 05$ & The unwanted record: 116 nurses succumbed to COVID-19 in Brazil. & Multimidia Internet \\
\hline 66 & Folha de São Paulo & $17 / 05$ & Enfermeiros sob Risco. & Jornal - Internet \\
\hline 67 & Wall Street Journal & $19 / 05$ & Brazil's Nurses Are Dying as COVID-19 Overwhelms Hospitals. & Jornal - Internet \\
\hline 68 & R7 & 19/05 & Brasil perde 106 profissionais de enfermagem no combate à COVID-19. & Internet \\
\hline 69 & Bloomberg & $21 / 05$ & COVID-19 Is Killing Nurses in Brazil More Than Anywhere Else. & Agência De Notícias -Internet \\
\hline 70 & Uol & $21 / 05$ & COVID: afastamento poderia ter salvo a vida de 43 enfermeiros, diz conselho. & Jornal Digital \\
\hline 71 & Uol & $21 / 05$ & Brasil lidera ranking de mortes de enfermeiros por coronavírus. & Jornal Digital \\
\hline 72 & 0 Globo & $22 / 05$ & Brasil ultrapassa a marca de cem médicos mortos por COVID-19, dois por dia. & Jornal Internet \\
\hline 73 & Uol & $23 / 05$ & MPT investiga denúncia de máscaras sem filtro para COVID em hospitais do RJ. & Jornal Digital \\
\hline 74 & Folha de São Paulo & $26 / 05$ & $\begin{array}{l}\text { Conselho do Ministério da Saúde lança alerta depois de recorde mundial de } 150 \text { mortes de } \\
\text { enfermeiros no Brasil. }\end{array}$ & Jornal Internet \\
\hline 75 & EBC & $26 / 05$ & Mais de 5 mil profissionais de saúde serão contratados para o enfrentamento à COVID-19. & Agência De Notícias - Internet \\
\hline 76 & The Guardian & $27 / 05$ & "My mother was murdered": how COVID-19 stalks Brazil's nurses. & $\begin{array}{l}\text { Jornal } \\
\text { Internet }\end{array}$ \\
\hline 77 & G1 & $27 / 05$ & Brasil é o país com mais mortes de enfermeiros por COVID-19 no mundo, dizem entidades. & Jornal Digital \\
\hline 78 & SBT & $28 / 05$ & COVID-19: 165 Enfermeiros mortos no Brasil. & Tv \\
\hline 79 & Marie Claire & $29 / 05$ & Quem cuida dos filhos das enfermeiras durante a pandemia? & Revista -Internet \\
\hline 80 & R7 & $31 / 05$ & 0 índice de morte por coronavírus dos profissionais de enfermagem brasileiros é o maior do mundo. & Jornal Digital \\
\hline
\end{tabular}

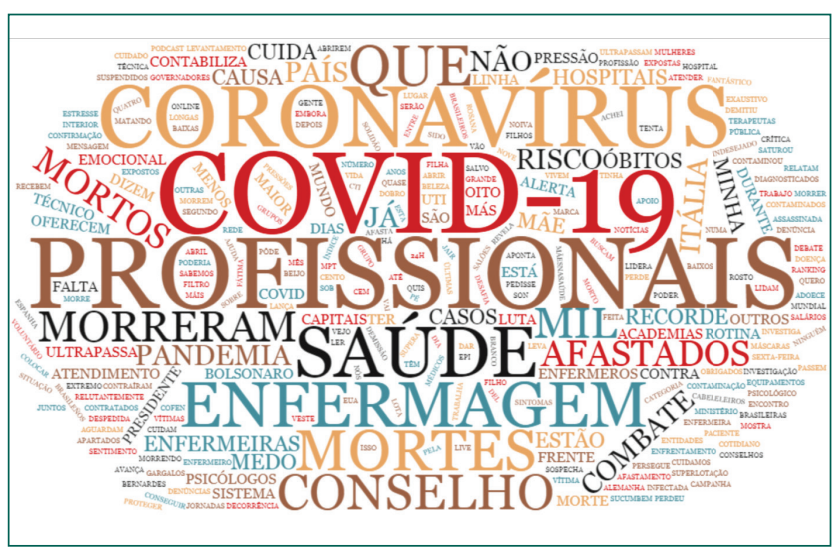

Figura 3. Nuvem de palavras representativa da Categoria 3 Vulnerabilidade, Adoecimento e Morte de Profissionais de Enfermagem
A cobertura dos óbitos e afastamento do serviço dos profissionais de Enfermagem contaminados mantém trajetória crescente entre abril e maio, sendo frequente uma abordagem mais aprofundada, abordando aspectos como a disponibilização de EPI, bem como os medos e anseios, a possibilidade de contaminação e exposição de membros da família, os conflitos de jornadas de trabalho e as questóes relacionadas às demandas socioeconômicas destes profissionais. Passa a haver divulgação, também, de outras iniciativas, como a solidariedade da Enfermagem, que oferece atendimento qualificado voltado aos profissionais que estão na linha de frente do combate à pandemia. 


\section{Discussão}

A Enfermagem representa aproximadamente 59\% da força de trabalho da saúde mundial, possuindo papel central na consecução da cobertura universal dos sistemas de saúde e no alcance dos Objetivos do Desenvolvimento Sustentável (ODS) e de metas nacionais e globais relacionadas a uma série de prioridades de saúde, dentre elas, respostas às emergências, a exemplo as de Saúde Pública. ${ }^{(13)}$

No Brasil, a Enfermagem congrega mais de dois milhôes de profissionais, entre enfermeiros (569.189), técnicos de enfermagem (1.330.447) e auxiliares de enfermagem (421.581), ${ }^{(14)}$ sendo o maior contingente de trabalhadores do macro setor Saúde. A pesquisa Perfil da Enfermagem no Brasil $^{(15)}$ realizada antes da pandemia, apontou que esses profissionais: trabalham muito e intensamente e ganham mal; em decorrência dos baixos salários, recorrem ao multiemprego, para complementação do rendimento mensal, quase sempre em condiçóes precárias; o desemprego estrutural é uma realidade, chegando a quase $20 \%$ em alguns estados; o sentimento de desvalorização do seu trabalho pela população é sentido por mais da metade do contingente; a maioria não se sente protegida em seu ambiente trabalho, sendo que $20 \%$ já sofreu violência e agressôes (físicas, verbais ou psicológicas) no ambiente de trabalho; $60 \%$ relatam desgaste profissional; e $10 \%$ informam ter sofrido acidente de trabalho recente.

A Enfermagem vivencia a inexistência de uma política salarial, a precarização das condiçóes de contratação e de trabalho, o incremento da terceirização, vulnerabilidade social e econômica, fomentada pelas políticas neoliberais, e o com o aumento da crise econômica no País, a renda tem caído e o valor real do salário diminuído, levando os trabalhadores da Enfermagem a dupla ou tripla jornada de trabalho. ${ }^{(16)}$

A situação pandêmica da COVID-19 levou as Naçôes a buscarem organizar seus sistemas nacionais de saúde para a mitigação da doença. Tal situação rapidamente mostrou as necessidades e fragilidades dos sistemas de saúde, inclusive sobre a proteção e saúde dos profissionais da saúde. No Brasil não foi diferente, logo foi percebida a vulnerabilidade dos profissionais de Enfermagem, médicos, fisiotera- peutas, bem como outros trabalhadores da saúde, derivada, sobretudo, pela sobrecarga e precarização das condiçóes de trabalho, da dificuldade de acesso aos EPI, entre outros motivos.

A Enfermagem brasileira, que já vinha vulnerável a diversos aspectos relacionados às condiçôes de trabalho, como apontado pela pesquisa do Perfil da Enfermagem no Brasil, ${ }^{(15)}$ e com sua essencialidade para cumprir a promessa de "não deixar ninguém para trás”, (13) com a pandemia da COVID-19 tal situação se acirrou tanto numa perspectiva do escopo de práticas, quanto em decorrência da amplitude e magnitude da doença, por conta destes profissionais estarem na linha de frente (front) atuando no cuidado, vigilância e monitoramento de casos da COVID-19 nos diferentes pontos da Rede de Atenção à Saúde (RAS), seja ela pública (Sistema Único de Saúde, o SUS) ou privada/filantrópica.

De acordo com o extrato de matérias observado na imprensa nacional e internacional sobre as condiçôes de trabalho e o número de óbitos, o principal temor dos profissionais da Enfermagem é de se contaminar e colocar em risco os pacientes e seus familiares, dada a alarmante falta de acesso ou inadequação dos EPI.

No mês de março, quando a pandemia no Brasil ainda estava na fase inicial e a primeira morte por COVID-19 no país foi registrada, no dia 17 , reportagem do Fantástico (22/03), ${ }^{(17)}$ na TV Globo, mostrou a rotina e os desafios dos profissionais da Enfermagem. Uma reportagem na BBC $(24 / 03)^{(18)}$ evidenciou o medo dos trabalhadores da linha de frente, quando ainda se sabia pouco sobre a doença e a necessidade vital da utilização de EPI. O título da matéria, "Cuidamos dos outros, mas ninguém cuida de nós", chama para o depoimento de uma enfermeira que foi infectada ao tratar de um paciente, em hospital privado, ambos sem usar máscara. $\mathrm{O}$ conteúdo do texto revela a ponta do iceberg, mostrando o despreparo do hospital e o total desconhecimento sobre a gravidade da doença no Brasil, naquele momento, em que a profissional foi orientada pela instituição a não usar o material de proteção "para não assustar os pacientes". A matéria apontava para a necessidade urgente de EPI, situação esta que se agravaria. 
No início de abril, o jornal El País Brasil ${ }^{(19)} \mathrm{pu}-$ blicou uma reportagem com o título "Sem material de proteção, profissionais de saúde relatam apreensão, após mortes de dois enfermeiros em São Paulo". Naquele começo de abril, o Brasil registrava 7.910 casos confirmados e 299 óbitos por coronavírus, e o Ministério da Saúde reconhecia a dificuldade na compra de EPI, a exemplo de máscaras, devido ao superaquecimento da demanda internacional pela pandemia, além do reconhecido déficit de testes para detectar a doença e a demora em se obter os resultados dos exames realizados.

O tema foi ganhando mais e mais espaço na mídia, com alertas em matérias, relatando que as denúncias sobre a falta de EPI aumentaram em 14\%. $\mathrm{Na}$ segunda semana de abril, os jornais O Globo ${ }^{(20)}$ e o Estadão ${ }^{(21)}$ deram destaque aos óbitos e a falta de EPI, noticiando a morte de 29 profissionais da saúde e mais de 3.600 denúncias relacionadas a situação de risco dos trabalhadores da linha de frente. Em 11 de abril, o Fantástico denunciou as mortes destes profissionais.

A Folha de S. Paulo (17/05) ${ }^{(22)}$ destacou dias depois a questão da falta de EPI com a matéria "Enfermeiros sob risco". Na imprensa internacional, o The Wall Street $(19 / 05),{ }^{(23)}$ de Nova York, abordou a morte das enfermeiras brasileiras diante das condiçóes precárias de trabalho na pandemia com a matéria: "Brazil's Nurses Are Dying as Covid-19”. O International Council of Nurses (ICN) alerta que os enfermeiros foram "cruelmente expostos ao perigo devido à falta de EPI adequado e de alta qualidade". ${ }^{(24)}$

Diante do aumento de casos de óbitos, quando as reportagens migram para esse registro, a carência de EPI aparece como uma das causas que colaboraram para o adoecimento e morte dos profissionais da Enfermagem. A falha na proteção dos profissionais da saúde tem contribuído para a disseminaçáo da doença, também a partir dos serviços de saúde. ${ }^{(25)}$ Aliado a todo esse panorama, no Brasil ainda incide o "subdimensionamento das equipes e manutenção de profissionais integrantes dos grupos de maior risco na linha de frente do atendimento". (26)

Com a expansão da pandemia, o acesso a EPI pelos profissionais da saúde tornou-se uma preocupação mundial importante. Equipes passaram a realizar atedimento a população supostamente infectada, enquanto aguardavam o acesso a EPI, ou então os que estavam disponíveis, não atendiam aos requisitos mínimos de segurança. Por conta disso, os profisisonais da saúde passaram a manifestar o medo e o receio de contaminar seus familiares. ${ }^{(27)}$

A escassez internacional de insumos e EPI necessários para o combate à pandemia, agravada pela disputa comercial entre os países, causou preocupação internacional; tanto que em 20 de abril, a Assembleia Geral da Organização das Naçóes Unidas (ONU) aprovou resolução, pedindo ação global para aumentar rapidamente o desenvolvimento, a fabricação e o acesso a medicamentos, vacinas e equipamentos, para enfrentar a pandemia do novo coronavírus. ${ }^{(28)}$

As matérias também abordaram o fato de que muitos profissionais integrantes de grupos de risco - idosos e portadores de comorbidades, que deveriam ter sido afastados da linha de frente do combate à COVID-19, seguiram trabalhando. A maioria dos profissionais de Enfermagem que foram a óbito durante os meses de março e abril de 2020, por suspeita e confirmação da COVID-19, pertencia a este grupo. Nesse sentindo, uma das reportagens mais contundentes é do The Guardian (27/05), ${ }^{(29)}$ em que a filha de uma enfermeira que fazia parte do grupo de risco, afirma: "Minha mãe foi assassinada". O título se desdobra na linha fina: "Como a COVID-19 persegue as enfermeiras no Brasil ("My mother was murdered': how COVID-19 stalks Brazil's nurses"). A matéria relata ainda que, "de acordo com o Conselho Internacional de Enfermeiras (ICN), isso significa que mais enfermeiras morreram no Brasil do que em qualquer outro lugar do mundo - incluindo outros hotspots de coronavírus, como os EUA, onde pelo menos 146 morreram, e o Reino Unido, onde o número é de pelo menos 77 ”.

$\mathrm{O}$ avanço dos casos de doentes e morte por COVID-19 entre os profissionais da Enfermagem, o medo de contraí-la ou de transmiti-la para os familiares, a sobrecarga de trabalho, e a dificuldade de acesso e a falta de EPI adequados e de alta qualidade tem levado muitos a transtorno mental. A afetação da saúde mental dos profissionais leva muitos a abondonarem os postos de trabalho, pedirem 
demissão e a desenvolverem depressão ou síndrome do pânico.

Estudo multicêntrico desenvolvido com 906 profisisonais da saúde (enfermeiros, médicos, outros profissionais da saúde, administradores, funcionários administrativos e trabalhadores de manutenção) de cinco grandes hospitais, envolvidos no atendimento a pacientes com COVID-19, em Cingapura e na Índia, apontou que 5,3\% apresentaram depressão moderada a muito grave, $8,7 \%$ ansiedade moderada a extremamente grave, 2,2\% estresse extremamente severo de moderado a grave e $3,8 \%$ para níveis moderados a graves de sofrimento psíquico. Da amostra do estudo, 39,2\% (355) eram enfermeiros. ${ }^{(30)}$

Este estudo transversal comparando dois grupos de enfermeiros: os da linha de frente (grupo de exposição) e outros que trabalham nas enfermarias habituais (grupo sem exposição) realizado na cidade de Torbat Heydariyeh, Irã, apontou que os escores de estresse no trabalho e Burnout no grupo de exposição à infecção por COVID-19 foram significativamente maiores do que no grupo sem exposição ( $p=0.006$ e $p=0,002$, respectivamente). Apesar da análise de regressão univariada do status de emprego $(p=0.047)$, experiência no atendimento a pacientes confirmados ou suspeitos de infecção por COVID-19 $(p=0.006)$, recursos hospitalares $(p=0.047)$ e estresse no trabalho $(p<0.001)$ foram considerados fatores de risco significativos para Burnout relacionados ao COVID-19. Na análise de regressão multivariada, o estresse no trabalho ( $p=0.031, \beta=0.308)$ foi considerado um fator único que possui uma relaçáo significativa com a exaustão relacionada ao COVID-19 da linha de frente, sendo que o fator que mais influenciou foi o estresse no trabalho. ${ }^{(31)}$

Recentemente, entre 16 a 18 de junho de 2020, ocorreu a 8a "Reuniáo da Tríade" - a OMS, o ICN e o International Confederation of Midwives $(I C M)$, congregando mais de 600 chefes de governo, enfermeiros e parteiras, líderes e representantes de Associaçôes Nacionais de Enfermagem, Centros Colaboradores da OMS para Enfermagem e Obstetrícia, órgãos reguladores e a campanha Nursing Now de 145 países. O relatório da reunião destacou que os "enfermeiros e parteiras colocam suas vidas em risco para responder à pandemia e fornecer serviços essenciais de saúde". O Encontro da Tríade focou "em como os enfermeiros e parteiras podem ser protegidos, sua liderança mantida e apoiada e suas contribuiçóes à resposta a emergências, a cobertura universal de saúde e mais saúde e bem-estar maximizados agora e no futuro". ${ }^{(32)}$

No contexto da pandemia, por conta das jornadas de trabalho dobradas, muitas vezes sem os EPI necessários, os profissionais da saúde ganharam, cada vez mais, na mídia, a aura de heróis. Como evidencia a reportagem da Exame (08/05), ${ }^{(33)}$ mostrando uma obra inédita do grafiteiro britânico Bansky, em homenagem às enfermeiras: "Obra de Bansky mostra enfermeiras como heroínas da vida real”. A obra, assinada pelo mais conhecido e mais anônimo grafiteiro do Reino Unido, mostra uma criança deixando de lado super-heróis como Batman e Homem Aranha e escolhendo uma profissional da saúde como inspiração.

Mesmo assim, fatos lamentáveis ocorreram com os profissionais da Enfermagem, como as agressōes sofridas quando realizavam ato pacífico em homenagem aos colegas mortos por COVID-19, em primeiro de maio (Dia Internacional do Trabalho), na Esplanada dos Ministérios, em Brasília (DF). O que contribuiu para disparar o número de reportagens abordando de forma explícita a atuaçáo do COFEN, que realizou denúncia contra os agressores. Foi também a semana em que o número de óbitos de profissionais de Enfermagem ultrapassou uma centena e começou a chamar ainda mais atenção da imprensa nacional e internacional.

As nuvens de palavras nas figuras apresentadas corroboram com esta discussão. Na categoria 1 apareceram em destaque as palavras Saúde-EnfermeirosMorte-Enfermagem- Conselho, mostrando que as reportagens enfatizavam na categoria os aspectos extremos de saúde e morte e destacando o Cofen. Já na categoria 2 as palavras mais destacadas foram Profissionais-Coronavírus-Covid19-Falta-ProteçãoDenúncias, enfatizando a triste realidade da falta de pessoal e de insumos. E na categoria 3 as mais visualizadas foram novamente Profissionais-SaúdeMortes-Coronavírus-Covid 19-Conselho. 
Importante destacar, que a Enfermagem historicamente tem apresentado forte protagonismo nos diversos sistemas de saúde mundiais, sobretudo em locais remotos, em situação de calamidade, desastres, guerras, ataques terroristas e pandemias. Apesar desse importante protagonismo sanitário, o componente político ainda necessita ser ampliado, devendo sair da condição de invisibilidade para os holofotes, com forte liderança e empoderamento.

Quanto à invisibilidade, em nível mundial, desde o ano de 2018, vem ocorrendo a Campanha Nursing Now, uma parceria entre a OMS e o ICN, que busca elevar o perfil e o status da Enfermagem global, por meio da capacitaçáo de "enfermeiros para que possam dar uma contribuição ainda maior para a melhoria da saúde em todo o mundo", assumindo um "papel ainda mais influente no enfrentamento dos desafios de saúde do século 21. Nursing Now coloca ênfase particular em estender a influência da Enfermagem sobre as políticas, desenvolver liderança e construir uma base de evidências mais forte para compreender o triplo impacto da Enfermagem na saúde, no empoderamento das mulheres e na economia”. Esse protagosimo, influência e liderança vêm ocorrendo com a forte inserção da Enfermagem no front da pandemia da COVID-19. ${ }^{(34)}$

O ICN ${ }^{(35)}$ em abril divulgou 12 principais prioridades para o combate à pandemia da COVID-19 em nível mundial, sobretudo para a força de trabalho em Enfermagem que atua em países com alta carga da doença. Dentre elas, com base nos resultados deste estudo, destacamos duas prioridades, que seguem:

1) "Demonstrar apoio público e reconhecer o valor dos enfermeiros para a sociedade" - "Essa pandemia destacou a Enfermagem como nenhum de nós poderia ter previsto. Os enfermeiros são o maior grupo de profissionais da saúde e são críticos para a resposta da COVID-19, para manter os sistemas de saúde funcionando e para a saúde das populaçóes. $\mathrm{O}$ público tem um papel importante a desempenhar para manter seguras as enfermeiras e outros profissionais da saúde. Eles podem apoiar os enfermeiros e mostrar que os valorizam, continuando a seguir rigorosamente os mais recentes conselhos de saúde pública, como distanciamento físico e auto-isolamento"; e
2) "Capitalizar na liderança de Enfermagem" - "É imperativo que as enfermeiras líderes do mundo estejam envolvidas na tomada de decisóes sobre políticas e planejamento ao mais alto nível, para garantir que os sistemas de saúde sobrecarregados possam oferecer o melhor atendimento possível ao maior número de pacientes [...]”. Os Governos devem ver nas Agências Nacionais de Enfermeiros parceiros-chave "na formulação de políticas, juntamente com seus chefes de enfermagem e outros altos funcionários [...]". "Os sistemas de saúde e os formuladores de políticas devem aproveitar a experiência e apoiar os líderes de enfermagem em ambientes clínicos que estão gerenciando efetivamente vários aspectos da resposta a COVID-19".

Os enfermeiros estão totalmente engajados na resposta a COVID-19, sendo essenciais para os esforços de prevenção e resposta da pandemia, estando na linha de frente, executando um cuidado de primeira linha, especialmente para os casos complexos que requerem hospitalização. Representam um dos grupos de profissionais da saúde mais confiáveis, e devem advogar por respostas políticas locais, estaduais e nacionais ao surto de COVID-19. Um surto global requer a participação ativa da força de trabalho da Enfermagem no atendimento clínico, educação/ formação e no compartilhamento de informaçôes sobre saúde pública e políticas. O engajamento e protagonismo dos enfermeiros frente à pandemia, seja no desenvolvimento do cuidado ou açôes de controle para sua mitigação, os colocam como atores-chave no fim do surto. ${ }^{(36)}$ Para que isto ocorra, a Enfermagem brasileira e mundial necessita de apoio da população, dos políticos legisladores e dos governantes dos diversos níveis.

\section{Conclusão}

A emergência pandêmica da COVID-19 levou a Enfermagem a ser importante fonte midiática na Saúde Pública. A despeito de sua capilaridade e amplitude do escopo de práticas nos diferentes níveis atenção e cenários do SUS, com um impor- 
tante contingente de profissionais, a Enfermagem e suas entidades (conselhos profissionais, sindicatos e associaçóes) não têm tradicionalmente grande visibilidade na mídia nacional e internacional, mesmo em pautas diretamente associadas à profissão. A proeminência da Enfermagem na mídia, observada durante a pandemia, oferece uma perspectiva única de observação de seu impacto sobre a cobertura jornalística. A avaliação das reportagens permite, ainda, que se observem as razóes para tal alcance, tanto externas, associadas à gravidade da situação sanitária; quanto internas, resultantes da capacidade de gerar dados confiáveis e oferecer porta-vozes capacitados em uma situação emergencial, contribuindo para aperfeiçoar as estratégias de comunicação em saúde. Para além da visibilidade conquistada pelos profissionais da Enfermagem, durante a pandemia da COVID-19, o conteúdo maciço de reportagens demonstra que os principais veículos de comunicação de abrangência nacional e internacional contribuíram para sensibilizar a opinião pública sobre o avanço da doença entre os profissionais, revelando as condiçóes precárias que muitos deles desenvolvem suas práticas, ainda mais agravada durante a crise sanitária; além de mostrar ao mundo a importância e a atuação destes. As matérias fortaleceram as denúncias de insuficiência de EPI, jogando luz nas fragilidades do sistema de saúde (público e privado). O reconhecimento da opinião pública, conquistado com a insistente exposição na mídia, favorece a evolução de questóes caras a categoria, como o piso salarial e a jornada de trabalho de 30 horas, que, infelizmente, somente a partir de uma tragédia sanitária como essa passam a ser olhadas e abordadas com a atenção, o cuidado e o respeito que merecem.

\section{Colaborações}

Freire NP, Castro DA, Fagundes MCM, Ximenes Neto FRG, Cunha ICKO e Silva MCN participaram da concepção, análise e interpretação dos dados, redação e revisão do conteúdo intelectual até a versão final do manuscrito.

\section{Referências}

1. Ma J. Coronavirus: China's first confirmed Covid-19 case traced back to November 17. South China Morning Post. 2020 Mar 13 [cited 2020 June 12]. Available from: https://www.scmp.com/news/china/society/ article/3074991/coronavirus-chinas-first-confirmed-covid-19-casetraced-back

2. Croda J, Oliveira WK, Frutuoso RL, Mandetta LH, Baia-da-Silva DC, Brito-Sousa JD, et al. COVID-19 in Brazil: advantages of a socialized unified health system and preparation to contain cases. Rev Soc Bras Med Trop. 2020;53:e20200167.

3. World Health Organization (WHO). WHO Director-General's statement on IHR Emergency Committee on Novel Coronavirus (2019-nCoV). Geneva: WHO; 2020 [cited 2020 June 12]. Available from: https:// www.who.int/dg/speeches/detail/who-director-general-s-statementon-ihr-emergency-committee-on-novel-coronavirus-(2019-ncov)

4. Huang C, Wang Y, Li X, Ren L, Zhao J, Hu Y, et al. Clinical features of patients infected with 2019 novel coronavirus in Wuhan, China. Lancet. 2020;395(10223):497-506. Erratum in: Lancet. 2020 Jan 30.

5. Chan JF, Yuan S, Kok KH, To KK, Chu H, Yang J, et al. A familial cluster of pneumonia associated with the 2019 novel coronavirus indicating person-to-person transmission: a study of a family cluster. Lancet. 2020;395(10223):514-23.

6. World Health Organization (WHO). WHO Director-General's opening remarks at the media briefing on COVID-19. Geneva: WHO; 2020 [Cited 2020 June 12]. Available from: https://www.who.int/dg/ speeches/detail/who-director-general-s-opening-remarks-at-themedia-briefing-on-covid-19---11-march-2020

7. Rothan HA, Byrareddy SN. The epidemiology and pathogenesis of coronavirus disease (COVID-19) outbreak. J Autoimmun. 2020;109:102433. Review.

8. Correia MI, Ramos RF, Bahten LC. The surgeons and the COVID-19 pandemic. Rev Col Bras Cir. 2020;47:e20202536.

9. Limaye RJ, Sauer M, Ali J, Bernstein J, Wahl B, Barnhill A, Labrique A. Building trust while influencing online COVID-19 content in the social media world. Lancet Digit Health. 2020;2(6):e277-8.

10. Souadka A, Essangri H, Benkabbou A, Amrani L, Majbar MA. COVID-19 and Healthcare worker's families: behind the scenes of frontline response. EClinicalMedicine. 2020;23:100373).

11. Conselho Federal de Enfermagem (COFEN). Observatório de Enfermagem. Profissionais infectados com COVID-19 informado pelo serviço de saúde. Brasília (DF): COFEN; 2020 [citado 2020 Jul 11]. Disponível em: http://observatoriodaenfermagem.cofen.gov.br/

12. Minayo MC. 0 desafio do conhecimento: pesquisa qualitativa em saúde. São Paulo: Hucitec; 2014.

13. World Health Organization (WHO). State of the world's nursing 2020. Executive Summary. Investing in education, jobs and leadership. Geneva:WH0; 2020 [cited 2020 June 14]. Available from: https://apps. who.int/iris/bitstream/handle/10665/331673/9789240003293-eng. pdf

14. Conselho Federal de Enfermagem (COFEN). Enfermagem em Números. Brasília (DF): COFEN; 2020 [citado 2020 Jun 10]. Disponível em: http://www.cofen.gov.br/enfermagem-em-numeros

15. Machado MH. Pesquisa perfil da enfermagem no Brasil: relatório final. Rio de Janeiro: COFEN/ FIOCRUZ; 2017 [citado 2020 Jun 10]. Disponível em: www.cofen.gov.br/perfilenfermagem/pdfs/relatoriofinal. pdf 
16. Ximenes Neto FR, Pessoa CV, Teixeira IX, Machado MH, Oliveira EN, Cunha IC. Características de enfermeiros da Estratégia Saúde da Família de uma Microrregião da Saúde do Ceará. Enferm Foco 2019; 10(5):130-6.

17. Rede Globo de Televisão. Fantástico. Drauzio Varella mostra os profissionais de saúde que estão combatendo o coronavírus [vídeo]. 22 de Março de 2020. Rio de Janeiro: Globo; 2020 [citado 2020 Jun 10]. Disponível em: https://globoplay.globo.com/v/8421715/

18. Gragnani J. Cuidamos dos outros, mas ninguém cuida de nós: as enfermeiras expostas ao coronavírus por falta de equipamentos. BBC News Brasil em Londres. 22 de Março de 2020. São Paulo: BBC; 2020 [citado 2020 Jun 10]. Disponível em: https://www.bbc.com/ portuguese/brasil-52023278

19. Oliveira J. Sem material de proteção, profissionais de saúde relatam apreensão após mortes de dois enfermeiros em São Paulo. El País. 22 de Abril de 2020. Espanha: El País; 2020 [citado 2020 Jun 3]. Disponível em: https://brasil.elpais.com/sociedade/2020-04-03/semmaterial-de-protecao-profissionais-de-saude-relatam-apreensaoapos-mortes-de-dois-enfermeiros-em-sao-paulo.html

20. Azevedo E. No Brasil, 14 enfermeiros morreram por coronavírus, e outras 12 mortes estão em investigação. Jornal 0 Globo. 13 de Abril de 2020. Rio de Janeiro: 0 Globo; 2020 [citado 2020 Jun 3]. Disponível em: https://oglobo.globo.com/sociedade/coronavirus/no-brasil-14enfermeiros-morreram-por-coronavirus-outras-12-mortes-estao-eminvestigacao-24369384

21. Vassalo JP. Coronavírus: Conselho revela 29 mortes de enfermeiros, e 3,6 mil denúncias por falta EPIs. Jornal o Estado de São Paulo. 14 de Abril de 2020. São Paulo: Estadão; 2020 [citado 2020 Jun 3]. Disponível em: https://politica.estadao.com.br/blogs/fausto-macedo/ coronavirus-conselho-revela-29-mortes-de-enfermeiros-e-36-mildenuncias-por-falta-epis/

22. Tarran E. Enfermeiros sob risco. Número elevado de mortes na pandemia evidencia condições de trabalho precárias. Folha de São Paulo. 17 de Mario de 2020. São Paulo: Folha de São Paulo; 2020. Disponível em: https://www1.folha.uol.com.br/opiniao/2020/05/ enfermeiros-sob-risco.shtml

23. Wall Street Journal. Brazil's nurses are dying as Covid-19 overwhelms hospitals. New York: Wall Street Journal; 2020 [cited 2020 June 3]. Available from: http://apkmetro.com/brazils-nurses-are-dying-ascovid-19-overwhelms-hospitals/

24. International Council of Nurses (ICN). ICN highlights top priorities to beat COVID-19.Geneva: ICN; 2020. [cited 2020 July 10]. Available from: https://www.icn.ch/news/icn-highlights-top-priorities-beatcovid-19
25. Silva AA. On the possibility of interrupting the coronavirus (COVID-19) epidemic based on the best available scientific evidence. Rev Bras Epidemiol. 2020;23:e200021.

26. Minayo MC, Freire NP. The pandemic exacerbates health inequalities. Ciên Saúde Coletiva. 2020;25(9):3555-6.

27. The Lancet. COVID-19: protecting health-care workers [editorial]. Lancet. 2020;395(10228):922.

28. United Nations (UN). General Assembly of the United Nations President of the 74th session. International cooperation to ensure global access to medicines, vaccines and medical equipment to face COVID-19. 2020 Apr 20. New York: United Nations; 2020 [cited 2020 July 12]. Available from: https://www.un.org/pga/74/2020/04/20/ international-cooperation-to-ensure-global-access-to-medicinesvaccines-and-medical-equipment-to-face-covid-19-2/

29. The Guardian. 'My mother was murdered': how Covid-19 stalks Brazil's nurses. [cited 2020 July 12]. Available from: https://www.theguardian. com/world/2020/may/27/brazil-coronavirus-nurses-deaths-cases

30. Chew NW, Lee GK, Tan BY, Jing M, Goh Y, Ngiam NJ, et al. A multinational, multicentre study on the psychological outcomes and associated physical symptoms amongst healthcare workers during COVID-19 outbreak. Brain Behav Immun. 2020;88:559-65.

31. Sarboozi Hoseinabadi T, Kakhki S, Teimori G, Nayyeri S. Burnout and its influencing factors between frontline nurses and nurses from other wards during the outbreak of coronavirus disease -COVID-19- in Iran. Invest Educ Enferm. 2020;38(2):e3.

32. World Health Organization (WHO). 2020 Triad Statement. International Council of Nurses. International Confederation of Midwives. Geneva: WHO; 2020 Jun 28 [cited 2020 July 7]. Available from: https://www. who.int/publications/m/item/2020-triad-statement

33. Doliveira M. Obra de Banksy mostra enfermeiras como heroínas da vida real. Exame. 8 de Maio de 2020 [citado 2020 Jul 12]. Disponível em: https://exame.com/estilo-de-vida/obra-de-banksy-mostra-enfermeirascomo-heroinas-da-vida-real/

34. Crisp N, Iro E. Nursing Now campaign: raising the status of nurses. Lancet. 2018;391(10124):920-1.

35. International Council of Nurses (ICN). ICN call to action: COVID-19. Geneva: ICN; 2021 [cited 2020 July 10]. Available from: https://www. icn.ch/system/files/documents/2020-04/ICN\%20briefing_COVID19_ Top_priorities_ENG.pdf

36. Choi KR, Skrine Jeffers K, Cynthia Logsdon M. Nursing and the novel coronavirus: risks and responsibilities in a global outbreak [editorial]. J Adv Nurs. 2020;76(7):1486-7. 